\title{
Ausländisches Recht im deutschen und englischen Zivilprozess
}

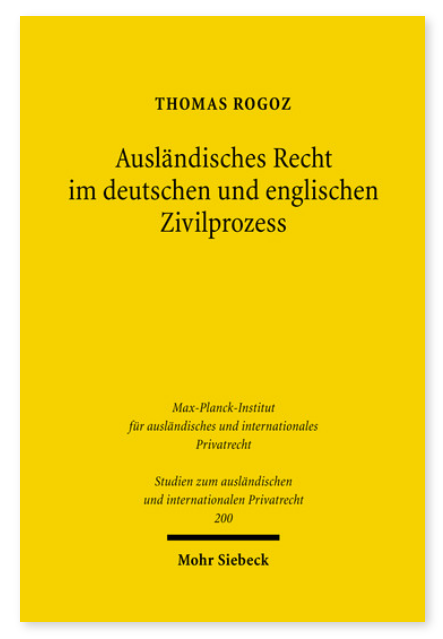

2008. XX, 244 Seiten. StudIPR 200

ISBN 978-3-16-151385-5

DOI 10.1628/978-3-16-151385-5

eBook PDF 74,00€

ISBN 978-3-16-149656-1

fadengeheftete Broschur 74,00€
Das deutsche Internationale Privatrecht lässt ausländische Rechtsordnungen großzügig zur Anwendung kommen. In Kombination mit der fortschreitenden Globalisierung führt dies dazu, dass deutsche Zivilgerichte ihren Urteilen zunehmend ausländisches Recht zugrunde legen müssen.

Thomas Rogoz beleuchtet in der vorliegenden Monographie zunächst, welchen dogmatischen Schwierigkeiten deutsche Richter hierbei ausgesetzt sind: Einerseits soll ausländisches Recht nicht hinter inländischem Recht zurückstehen. Und so ist der Richter nicht nur dafür verantwortlich, dass ausländisches Recht zur Anwendung kommt, sondern auch dafür, dass es richtig ermittelt wird. Er steht also vor dem Problem, wie französisches Erbrecht, türkisches Scheidungsfolgerecht oder japanisches Vertragsrecht richtig anzuwenden sind. Andererseits liegt auf der Hand, dass iura novit curia schon angesichts der Sprachbarriere keine Geltung beanspruchen kann. Der rechtsvergleichende Blick nach England zeigt, dass dogmatische Schwierigkeiten kaum aufkommen, wenn man ausländisches Recht als Tatsache ansieht. Dort obliegt es den Parteien, ausländisches Recht darzulegen und zu beweisen. Andernfalls entscheidet das Gericht nach common law.

Abschließend gibt Thomas Rogoz dem Leser anhand der aktuellen Rechtsprechung praktische Lösungen an die Hand, wie der Inhalt ausländischen Rechts in den Prozess eingeführt werden kann. Dabei legt er sein besonderes Augenmerk auf den Sachverständigenbeweis. Der Vergleich mit England offenbart die Schwächen und Stärken dieses Beweismittels.

Thomas Rogoz Geboren 1978; Studium der Rechtswissenschaften und der Betriebswirtschaftslehre in Erlangen-Nürnberg; 2008 Promotion; seit 2007 Staatsanwalt bei der Staatsanwaltschaft Nürnberg-Fürth.

Jetzt bestellen:

https://mohrsiebeck.com/buch/auslaendisches-recht-im-deutschen-und-englischen-zivilprozess-9783161513855?no_cache=1 order@mohrsiebeck.com

Telefon: +49 (0)7071-923-17

Telefax: +49(0)7071-51104 